\title{
Editorial
}

\section{Neurosciences and Neuro post-COVID-19}

\author{
Ricardo F. Allegri ${ }^{1}$ \\ Fabian Roman ${ }^{2}$ \\ Ernesto Barceló ${ }^{3}$
}

How to cite this article:

Allegri, R. F.; Roman, F. \& Barcelo, E. (2021). Editorial. Neurosciences and Neuro post-COVID-19. Journal of Apllied Cognitive Neuroscience, 2(1), e00133715.

https://doi.org/10.17981/JACN.2.1.2021.01

COVID-19 pandemic is the world's greatest public health concern, at the same time with various stages depending on the regions. At the moment of this Editorial (01/06/21), 170 million people have been confirmed cases, which represents $2 \%$ of the population of the entire planet. World Health Organization-WHO estimates that $20 \%$ of the population has been infected and the numbers continue to grow (WHO, s.f.). Currently, three of the five countries with the highest number of cases are in Latin America (Brazil, Argentina, and Colombia) (Johns Hopkins University \& Medicine, s.f) (Figure 1).

\footnotetext{
${ }^{1}$ Instituto Neurológico Fleni, FAAN, Buenos Aires, Argentina. Contact mail: jacn@cuc.edu.co

ORCID: http://orcid.org/0000-0001-7166-1234

${ }^{2}$ Red Iberoamericana de Neurociencia Cognitiva, Buenos Aires,Argentina. ORCID: https://orcid.org/0000-0001-7741-3602

${ }^{3}$ Universidad de la Costa-CUC, Barranquilla, Colombia.

ORCID: https://orcid.org/0000-0001-5881-4654
} 


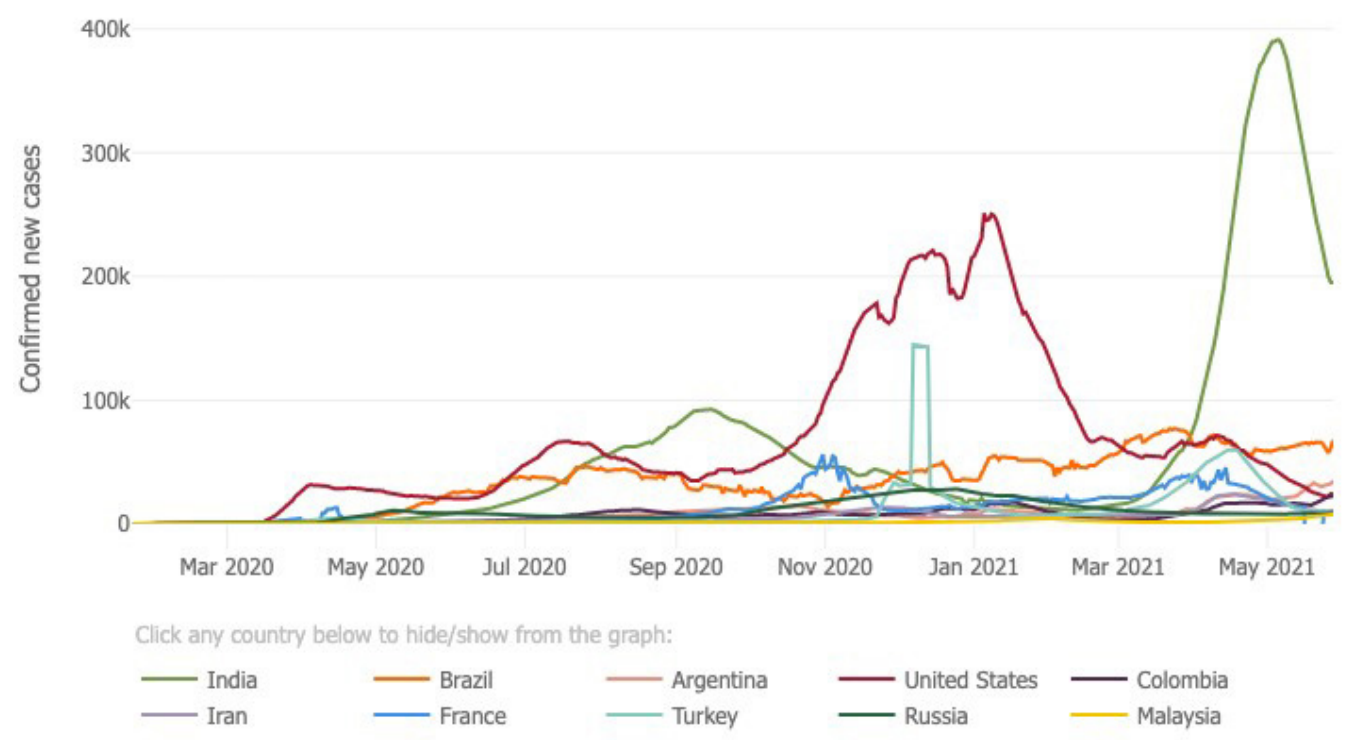

Figure 1. Daily Confirmed New Cases: Outbreak evolution for the current most affected countries (date 01/06/21).

Source: Johns Hopkins University \& Medicine (s.f.).

Public health has faced several key problems that this infection generates, on the one hand, the severity of the respiratory syndrome and with it the need for intensive care and the increase in morbidity and mortality; and on the other hand, the contagiousness of the picture that generates a rapid rise in the number of cases saturating the response capacity of the health system. Thus, the known effects of the virus were limited to a respiratory condition of variable severity.

At present, it is recognized that this situation will have an impact on health motivated by the virus itself and the described condition, an impact on the delay of the treatment of acute pathologies due to the saturation of the system (called the second wave of impact), a third impact motivated by the decompensation of chronic pathologies such as Alzheimer's disease or cardiovascular disease (hypertension, diabetes, dyslipidemia, etc.) that have not received the necessary control and a fourth wave due to psychiatric disorders that the catastrophic experience and the emotional impact of certain measures such as lockdown can bring in the long term (Allegri \& Sevlever, 2020) (Figure 2).

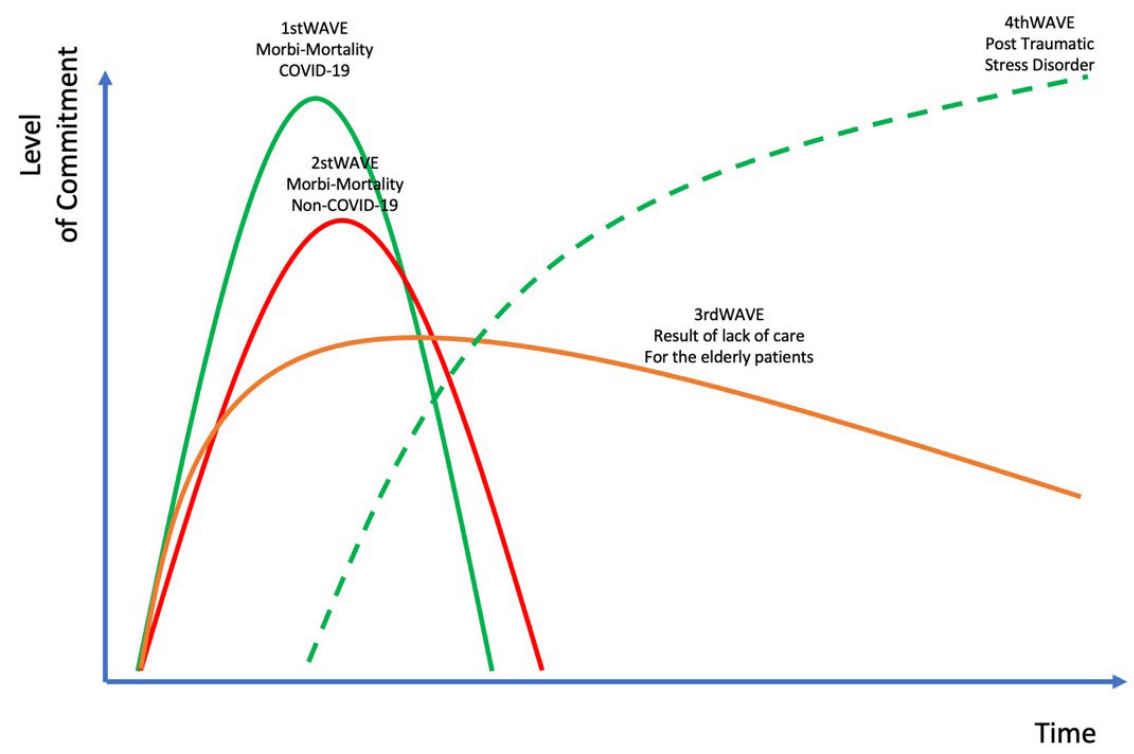

Figure 2. The four issues not to forget in Pandemics. Source: Authors. 
Despite this exhaustive theoretical scenario, the virus is considered a monophasic and acute entity, and its long-term impact on health are estimated based rather on system deficiencies or on the effects of the strategies implemented to reduce the first wave. However, there is no evidence, and it has not been considered in most scenarios, about the possibility that the virus could have a long-term impact, as it could increase the prevalence of certain syndromes and thus affect health general in a kind of five waves.

The absence of this evidence, on the other hand, is not necessarily an indication that these complications do not exist, only that this is a unique moment in the history of medicine where there are no previous experiences to assess it. However, other pandemic experiences in the past showed the possibility that these complications are a real problem and that they occur in the plan of neurological manifestations

A paradigmatic case was the Spanish influenza virus epidemics. Neurological complications as sequelae of influenza infection have been documented for more than a century. Henry, Smeyne, Jang, Miller \& Okun (2010) reported in a historical review, a document on Spanish influenza in 1918 where an association between neurological disorders, and the pandemic was established, detailing a temporal relationship between influenza outbreaks and meningitis, poliomyelitis and poliomyelitis encephalitis. Other neurological manifestations such as lethargic encephalitis and post-encephalitic Parkinsonism have been closely associated with the Spanish influenza pandemic.

On the other hand, there is also evidence of neurological complications in other Coronavirus epidemics. During the outbreaks of severe acute respiratory syndrome (SARS) in China (Tsai, Hsieh \& Chang, 2005; Xu et al., 2005; Lee et al., 203) and the Middle East Respiratory Syndrome-MERS in Saudi Arabia (Saad et al., 2014; Kim et al., 2017) neurological signs and symptoms were reported both in acute form (encephalitis, polyneuropathy, stroke, seizures, etc.) and subsequent neurological complications (neuropathies, myopathies, fatigue, myalgia, weakness, depression, and cognitive impairment), and varying degrees of evidence linking them directly with the viral infection. These become relevant in the theoretical framework due to the enormous similarity between the genome of both viruses and SARS-CoV-2 (the causal agent of Covid-19), as well as the transmission mechanism and clinical manifestations. This leads to thinking that some of this evidence is "transferable" when thinking about the future scenario of the pandemic by covid-19 (Figure 3).

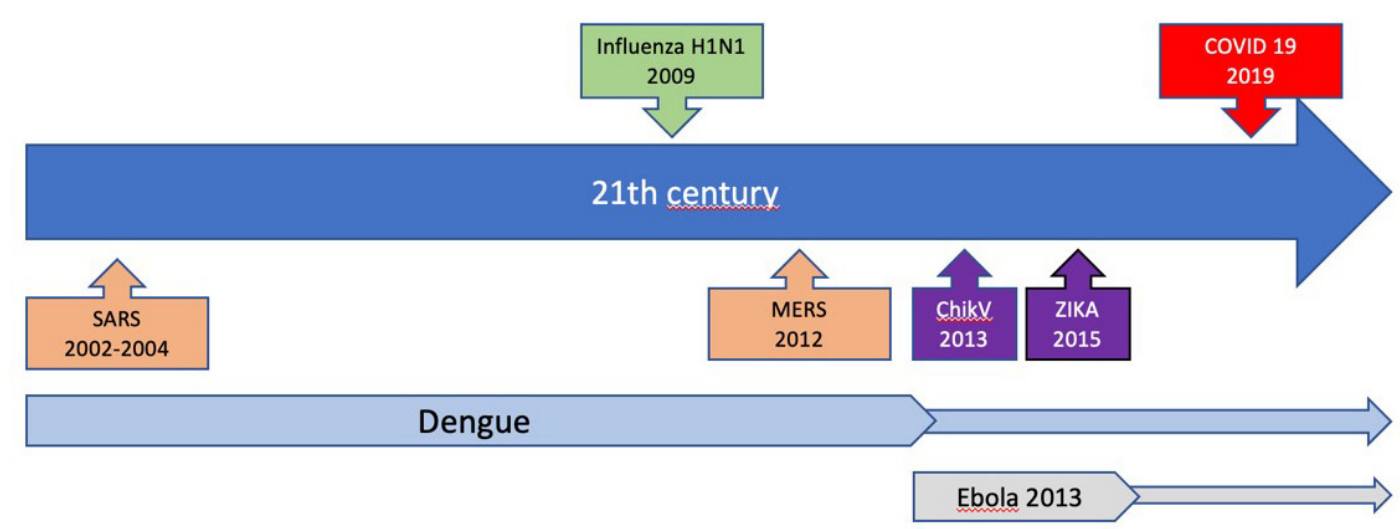

SARS-CoV-1 (2003) = encephalitis, stroke, sleep disorders, polineuropathies (Tsai et al., 2005)

MERS-CoV (2012) = seizures, encephalitis, cognitive deterioration, Guillain Barre syndrome (Saad et al., 2014)

Figure 3. Pandemics in the 21th century. Source: Authors. 
With the previously mentioned results, it is expected to find neurological involvement in patients with covid-19. In the context of a pandemic with a wide population diffusion, it is difficult to determine whether the symptoms detected are causality associated with the virus or simply concomitance; however, it is important to specify the findings that can clarify the neurological effect of the virus.

In this COVID-19 pandemic context, there are 3 types of neurological complications (Table 1):

TABLE 1.

Neurological Complication due or concomitant to COVID-19 pandemics.

\begin{tabular}{ll}
\hline Patients with previous neurological diseases & Dementia, Alzheimer`s Disease, Parkinson's Disease \\
\hline $\begin{array}{l}\text { Neurological complication in the context of } \\
\text { acute COVID }\end{array}$ & \\
Due to acute COVID & $\begin{array}{l}\text { Anosmia, ageusia, stroke, encephalitis, Guillain } \\
\text { Barre syndrome, neuropathies etc... }\end{array}$ \\
Patients in Critic Care & Stroke, myopathies, neuropathies, etc. \\
Neuro Post COVID & \\
Long COVID & $\begin{array}{l}\text { Headache, fatigue, anosmia, ageusia, cognitive } \\
\text { impairment, sleep disorders, dizziness, motor paresis, }\end{array}$ \\
Post COVID & neuropathies, etc. \\
\hline
\end{tabular}

Source: Authors.

\section{Patients with neurological diseases before the pandemic such as those with dementia in whom there is a greater risk of morbidity and mortality due to Covid-19 infection.}

This is because they are elderly patients and in these patients, the general morbidity and mortality of the virus is higher than in young patients (probably explain by the decline immune response or because they are confined in long term care homes or residences for the elderly where the chance of contagion is greater or even due to genetic predisposition as occurs with APOE e4 genotype (for which homozygosity is associated with Alzheimer disease and with severe COVID-19 illness.

\section{Patients with neurological complications in the context of acute Covid.}

In this case, the neurological complications may be due to the direct neurotropic effect, or to the indirect secondary impact induced by the virus, in terms of immunity, hypoxia, hypertension, systemic inflammatory reaction and other mechanisms, or to the frequent complications of the critical patient in intensive care units beyond of the causes.

So it can be divide in:

a. Acute Neuro-Covid linked to Covid infection: anosmia, ageusia, cerebrovascular accident, encephalitis, Guillain Barre syndrome, Myopathies, Neuropathies, etc. 
b. Acute neurological symptoms not linked to the virus: neurological symptoms or disease related with the Critical Patient: cerebrovascular accidents, fatigue, myopathies, etc.

The clinical complications related to acute COVID-19 involve the central and peripheral nervous systems. Regarding the central nervous system, headache has been reported in various series at a variable frequency between 89 and $98 \%$ of cases, sometimes as part of the febrile syndrome but in $22 \%$ of cases as the first manifestation of the infection.

One of the most characteristic acute conditions is anosmia. Due to the enormous frequency of this symptom, Li, Bai \& Hashikawa (2020) suggested that the viral neurotropism of COVID-19 could cause the invasion of the olfactory nerve, the rhinencephalon and then the brainstem acting as one more cofactor that would explain the typical respiratory failure of COVID-19.

There is sufficient evidence to ensure that COVID-19 may increase the risk of venous and arterial thromboembolism associated with inflammation, hypoxia, immobilization, and diffuse intravascular coagulation (Varga et al., 2020). There are few case series still reported but the evidence seems to suggest that there is an increased risk for a cerebrovascular disease that appears to exceed the aforementioned mechanisms (Li et al., 2020). Microvascular inflammation or increased platelet aggregation determined by alterations in virus-specific inflammation mediators have been suggested as possible causes.

A striking finding is the presence of cortical symptoms in patients infected with COVID-19. Helms et al. (2020), reported 58 patients with severe COVID-19. Neurological findings were found in $84 \%$ of patients at ICU admission, including agitation (69\%); signs of the corticospinal tract (67\%), such as hyperreflexia, clonus, and bilateral extensor plantar responses (Babinski sign); added to delirium in 65\% of cases. The presence of any neurological symptom, sign, or disease increases $37 \%$ the mortality (Beghi et al., s.f.). In one study, delirium was present in $73 \%$ of COVID+ patients with pre-existing dementia (Beghi et al., s.f.) (Figure 4).

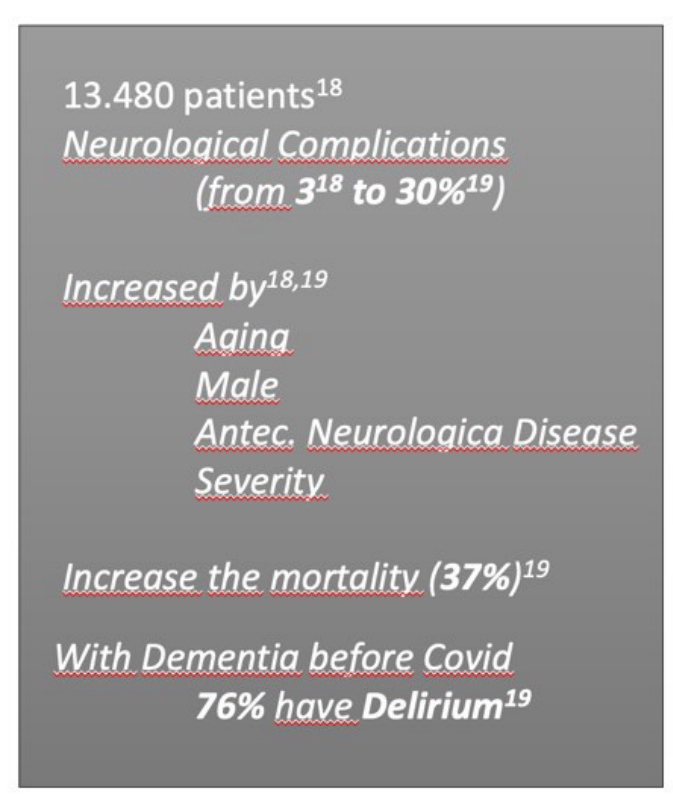

Figure 4. Neurological Findings in Acute COVID-19. Source: Authors.

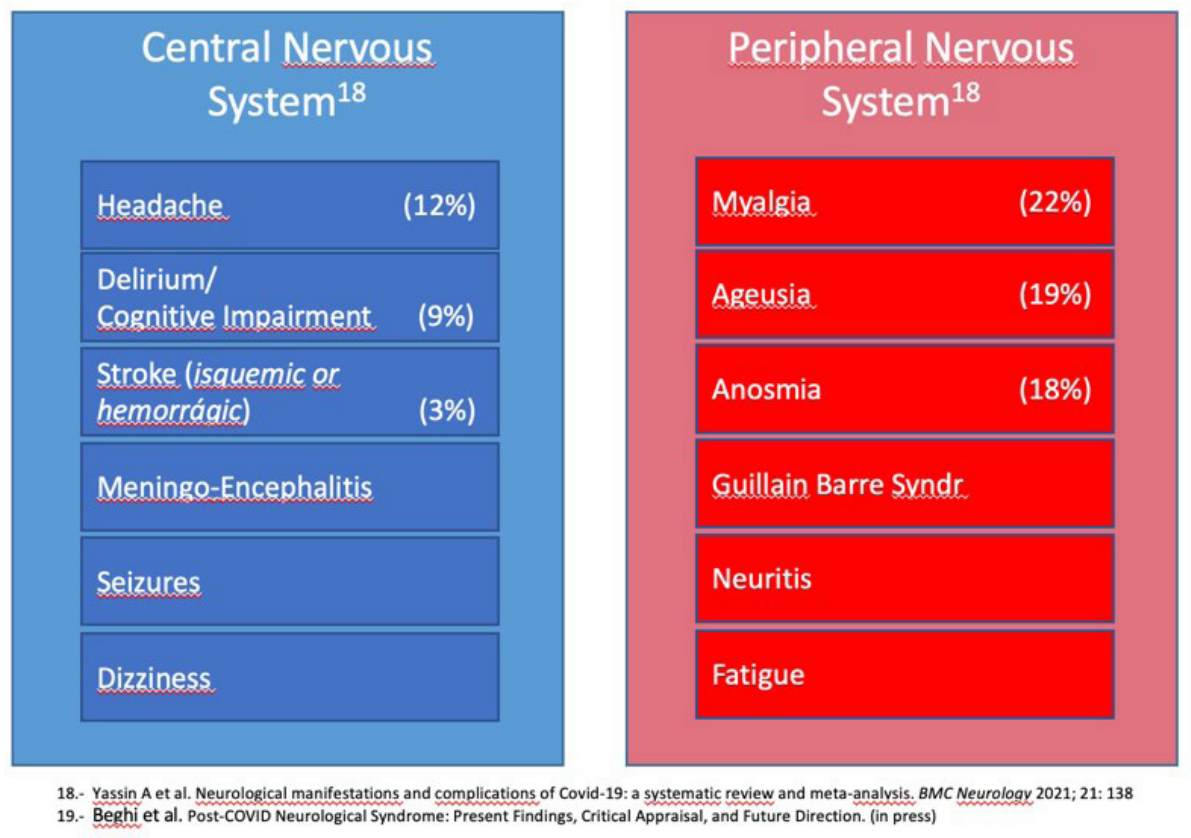

18.- Yassin A et al. Neurological manifestations and complications of Covid-19: a systematic review and meta-analysis. BM
19. Beghi et al. Post-CoviD Neurological Syndrome: Present Findings, Critical Appraisal, and Future Direction. (in press) 


\section{Patients with long-term neurological sequels of Covid-19}

In recent months, persistence, worsening, or new appearance of neurological symptoms have been described at 3 and 6 months after the acute episode (Taguet et al., 2021; Huang et al., 2021; Nersesjan et al., 2021).

At present, a specific phenotype that would specify a post-COVID (long-COVID) neurological syndrome has not yet been identified. However, registries and other surveillance systems have been activated in several countries, including follow-up visits, and will serve as important sources for the investigation of neurological disorders resulting as sequelae of this viral infection or occurring de-novo once the acute phase has elapsed (Begui et al., s.f.).

Huang et al. (2021) found 20\% neurological manifestations at 6 months, with $63 \%$ fatigue and muscle weakness, $26 \%$ sleep disorders, $24 \%$ gait disorders, and $23 \%$ anxiety and depression21. Nersesjan et al. (2021) evaluating patients who were hospitalized in intensive care units, 45\% had neurological disorders at 3 months, 31\% encephalopathy, 28\% cognitive impairment, $13 \%$ polyneuropathy, $11 \%$ gait disorder, $11 \%$ tetraparesis.

In the study by Taquet et al. (2021) out of 236, 370 patients at 6 months, the global incidence of neurological and psychiatric pathologies was $33 \%$ of those infected with symptoms, in those who were admitted to intensive care units the incidence was $46 \%$ and in those who had encephalitis $62 \%$. These authors showed a higher frequency of ACV, nerve, nerve root or plexus disorder, myoneural or muscle disease, dementia, mood, anxiety, or psychotic disorder.

Although the majority of people infected recover within weeks, many people experience persistent symptoms. Persistence of symptoms relating to COVID-19 infection for more than 28 days after diagnosis is Long COVID (Mendelson et al., 2020) and development of new symptoms or impairment of existing symptoms is named Post-COVID. Other authors define Long COVID or post-acute COVID (symptoms beyond 3 weeks) and chronic postCOVID syndrome (beyond 12 weeks) (Halpin, O'Connor \& Sivan, 2020).

$30 \%$ of post-COVID patients have shown poor concentration, cognitive impairment, behavioral changes, and psychological symptoms called "brain fog" (Stefano, Ptacek, Ptackova, Martin \& Kream, 2021). They describe cognitive functions that are energy sensitive become functionally disruptive, but we don't know the causes or treatments.

In one COVID-19 pandemic that affects more than $20 \%$ of the world population, with an uncertain but significant neurological impact on long-term health, we must ask ourselves what the correct approach to long-term or post-COVID-19 will be. Probably we need a multifaceted approach to tackle the post-COVID, a multidisciplinary team including neurology, psychiatry, neuropsychology, psychology and cognitive rehabilitation. Health systems around the globe needs to develop Post COVID clinics to prevent a future tsunami of chronic neurological disability (Halpin et al., 2020).

\section{REFERENCES}

Allegri, R.F. \& Sevlever, G. (2020). Invited Commentary: The elusive paradox: The woods behind the trees. [publicación blog]. Available:

https://blogs.neurology.org/author/ricardoallegri/ (Accessed 01/06/2021). 
Beghi, E.; Giussan, Gi.; Westenberg, E.; Garcia-Azorin, D.; Guekht, S.; Allegri, R. F.; Kivipelto, M.; Mangialasche, F.; Mukaetova-Ladinska, E.; Prasad, K. \& Winkler, A. (s.f.). Post-COVID Neurological Syndrome: Present Findings, Critical Appraisal, and Future Direction. (in press).

Halpin, S.; O'Connor, R. \& Sivan, M. (2020). Long COVID and chronic COVID syndromes. Journal of Medical Virology, (3), 1-2.

https://doi.org/10.1002/jmv.26587

Helms, J.; Kremer, S.; Merdji, H.; Clere, Jehl, R.; Schenck, M.; Kummerlen, C.; Collange, O.; Boulay, C.; Fafi-Kremere, S.; Ohana, M.; Anheim, M. \& Meziani, F. (2020). Neurologic features in severe SARS-CoV-2 infection. The New England Journal of Medicine, 382(23), 2268-2270.

https://doi.org/10.1056/NEJMc2008597

Henry, J.; Smeyne, R. J.; Jang, H.; Miller, B. \& Okun, M. S. (2010). Parkinsonism and neurological manifestations of influenza throughout the 20th and 21st centuries. Parkinsonism \& Related Disorders, 16(9), 566-571.

https://doi.org/10.1016/j.parkreldis.2010.06.012

Huang, C., Huang, L., Wang, Y., Li, X., Ren, L., Gu, X., Kang, L., Guo, L., Liu, M., Zhou, X., Luo, J., Huang, Z., Tu, S., Zhao, Y., Chen, L., Xu, D., Li, Y., Li, C., Peng, L., Li, Y., Xie, W., Cui, D., Shang, L., Fan, G., Xu, J., Wang, G., Wang, Y., Zhong, J,, Wang. C., Wang, J., Zhang, D. \& Cao, B. (2021). 6-month consequences of COVID-19 in patients discharged from hospital: a cohort study. Lancet, 397(10270), 220-232.

https://doi.org/10.1016/S0140-6736(20)32656-8

Johns Hopkins University \& Medicine. (s.f.). Coronavirus Resources Center. [Online]. Available:

https://coronavirus.jhu.edu/data/new-cases

Kim, J. E.; Heo, J. H.; Kim, H. O.; Song, S. H.; Park, S. S., Park, T. H., Ahn, J. Y.; Kim, M. K.; Choi, J. P. (2017). Neurological complications during treatment of Middle East respiratory syndrome. Journal of Clinical Neurology (Seoul, Korea), 13(3), 227-233. https://doi.org/10.3988/jcn.2017.13.3.227

Lee, N.; Hui, D., Wu, A.; Chan, P.; Cameron, P.; Joynt, G. M.; Ahuja, A.; Yung, M. Y.; Leung, C. B.; To, K. F.; Lui, S. F.; Szeto, C. C.; Chung, S. \& Sung, J. Y. (2003). A major outbreak of severe acute respiratory syndrome in Hong Kong. The New England journal of medicine, 348(20), 1986-1994.

https://doi.org/10.1056/NEJMoa030685

Li, Y. C.; Bai, W. Z. \& Hashikawa, T. (2020). The neuroinvasive potential of SARS-CoV2 may be at least partially responsible for the respiratory failure of COVID-19 patients, Journal of Medical Virology, 92(6), 552-555.

https://doi.org/10.1002/jmv.25728

Li, Y.; Wang, M.; Zhou,Y.; Chang, J.; Xian, Y.; Wang, D.; Mao, L.; Jin, H. \& Hu, B. (2020). Acute cerebrovascular disease following COVID-19: a single center, retrospective, observational study, Lancet, 5(3), 279-284.

https://doi.org/10.1136/svn-2020-000431 
Mendelson, M.; Nelm J.; Blumberg, L.; Madhi, S. A.; Dryden, M.; Stevens, W. \& Venter F. W. D. (2020). Long-COVID: An evolving problem with an extensive impact. South African Medical Journal, 111(1), 10-12. https://doi.org/10.7196/SAMJ.2020.v111i11.15433

Nersesjan, V.; Amiri, M.; Lebech, A.M.; Roed, C.; Mens, H.; Russell, L.; Fonsmark, L.; Berntsen, M.; Sigurdsson, S. T.; Carlsen, J.; Langkilde, A. R.; Martens, P.; Lund, E. L.; Hansen, K.; Jespersen, B.; Folke, M. N.; Meden, P.; Hejl, A. M.; Wamberg, C.; Benros, M.E. \& Kondziella, D. (2021). Central and peripheral nervous system complications of COVID-19: a prospective tertiary center cohort with 3-month follow-up. Journal of Neurology, 1-19.

https://doi.org/10.1007/s00415-020-10380-x

Saad, M.; Omrani, A. S.; Baig, K.; Bahloul, A.; Elzein, F.; Matin, M. A.; Selim, M. A. A.; Al Mutairi, M.; Al Nakhli, D.; Al Aidaroos, A. Y.; Al Sherbeeni, N.; Al-Khashan, H. I.; Memish, Z. A. \& Albarrak, A. M. (2014). Clinical aspects and outcomes of 70 patients with Middle East respiratory syndrome coronavirus infection: a single-center experience in Saudi Arabia. International Journal of Infectious Diseases, 29(C), 301-306. https://doi.org/10.1016/j.ijid.2014.09.003

Stefano, G. B.; Ptacek, R.; Ptackova, H.; Martin, A. \& Kream, R. M. (2021). Selective Neuronal Mitochondrial Targeting in SARS-CoV-2 Infection Affects Cognitive Processes to Induce 'Brain Fog' and Results in Behavioral Changes that Favor Viral Survival. Medical Science Monitor, 27, e930886-1- e930886-4.

https://doi.org/10.12659/MSM.930886

Taquet, M.; Geddes, J. R.; Husain, M.; Luciano, S. \& Harrison, P. J. (2021). 6-month neurological and psychiatric outcomes in 236379 survivors of COVID-19: a retrospective cohort study using electronic health records. Lancet Psychiatry, 8(5), 416-427. https://doi.org/10.1101/2021.01.16.21249950

Tsai, L.-K., Hsieh, S.-T. \& Chang, Y.-Ch. (2005). Neurological manifestations in severe acute respiratory syndrome. Acta neurologica Taiwanica, 14(3), 113-119. Available:

http:// w w w.ant-tnsjournal.com/ PastIs sues/index_Past Issues. asp? $\mathrm{xx}=2005 \& \mathrm{yy}=21 \& \mathrm{zz}=14 \& \mathrm{ww}=3$

Varga, Z.; Flammer, A. J.; Steiger, P.; Haberecker, M.; Andermatt, R.; Zinkernagel, A. S.; Mehra, M. R.; Schuepbach, R. A.; Ruschitzka, F. \& Moch, H. (2020). Endothelial cell infection and endotheliitis in COVID-19, Lancet, 395(10234), 1417-1418. https://doi.org/10.1016/S0140-6736(20)30937-5

Xu, J.; Zhong, J.; Liu, J.; Li, L.; Li, Y.; Wu, X.; Li, Z.; Deng, P.; Zhang, J.; Zhong, N.; Ding, Y. \& Jiang, Y. (2005). Detection of severe acute respiratory syndrome coronavirus in the brain: potential role of the chemokine mig in pathogenesis. Clinical Infectious Diseases, 41(8), 1089-1096.

https://doi.org/10.1086/444461

WHO. (s.f.). WHO coronavirus disease (COVI-19) dashboard. [Online]. Available: https://covid19.who.int/ (Updated 2021. Accessed 01/06/2021) 